\title{
Employee Turnover in Non-Profit Organizations in Jimma Prefecture, Ethiopia
}

\author{
Sherif Abagelan ${ }^{1} \quad$ Daniel Tadesse Tullu ${ }^{2}$ (Assistant Professor) \\ 1. Regional Project Facilitator at Ethiopian Center for Disability and Development, \\ 2. Ambo University, Department of Management
}

\begin{abstract}
This study aimed to investigate the factors that affects staff turnover in nonprofit organizations operate in Jimma area. Descriptive design was used. Data were collected via questionnaires with response rate of 93.5\%. Finding of the study revealed that Push factor (ineffective management: low salary and benefit: lack of career growth opportunity and job related problem) have pertinent significant impact on employee turnover. Furthermore, the study indicated there is positive correlation between employee turnover and personal, push and pull factors. The study recommends nonprofit sectors should invest more to leadership development program and prepare standard human resource policy and update: offer competitive salary and prepare career growth development opportunity to retain staff in the organization.
\end{abstract}

Keywords: Pull and push factors, Jimma, Non-governmental, turnover, Ethiopia

DOI: $10.7176 / \mathrm{JAAS} / 65-01$

Publication date:June $30^{\text {th }} 2020$

\section{Introduction}

Employee turnover is the number of permanent employees leaving the organization within the reported period versus the number of actual active permanent employees on the last day of the previous reported period. Armstrong, (2006) stated that employee turnover refers to the rate at which an employer gains and losses employee how long the staff leave and join the organization. The employers are more concerned with turnover as its impact negatively affect and expensive aspect. Thomas, (2003) stated that employee termination is continuous phenomenon that affects the organization results and creates negative impact on performance and success of the organization.

Nonprofit organizations are humanitarian institutions implementing in many countries of east Africa to support the poor community group and reduce poverty like any other areas of developing nations in the world (Taylor, 2010). Taylor further stated that high employee turnover is common occurrence and this is attributed to desire for more pay, improved environment, leadership structures and motivational reward among other issues. The success of NGOs is determined by capacity of skilled professionals' workers that undertake multiple tasks simultaneously without missing deadline. They recruit and select professionals from the labor market and train and orient them to the type of services they intent to the community where they work. However most of the NGOs are highly affected by staff turnover and subjected to financial and non-financial cost for replacing new worker to the organization. The expense of staff turnover facing the organization include advertising expenses, loss of time and efficiency, work imbalance fees and cost of training and development for new hired and bad relation with donor relationship indicated (Harrie, 2002). If the organization determines the most common causes of employee turnover, it would certainly able to take necessary steps for recruiting and retaining well-qualified personnel (Armstrong, 2009)

In addition, there might be service quality loss while assigning and employing replacement staff often the organization experience waste of time due to inexperienced replacement of staff. Management and other staff spend their valuable time not doing their job rather providing orientation to the new hired staff. Nonprofit organizations work on designing the retention strategies to reduce the rate of turnover for the employees so that the talent in the organization can be utilized in the best possible way.

\section{Problem Statement}

Employee turnover can be harmful to the organization efficiency if the skilled and experienced workers leave the organization and work population contain high percentage of novice worker (Armstrong, 2006).Efficiency and existence of the organization have been threatened by huge costs/expenditure incurred on recruitment and selection of new staff to replace the work force gap created by the leaving employees (Premeaux, 2000)

According to Maxwell (2010), the key problem to employees' turnover is that the organization loses the most experienced and skilled staffs that had invested heavily in training on various job task functions. Therefore, the organization forced to incur huge costs in terms of time and finance to train the newly recruited staff to make them effectively adapt the organization working environment and demonstrate the required skills and experience. According to Phillip (2009) employees turnover influences allocation of job task functions to inexperienced employees who lacks technical knowhow on effective execution of organization services which greatly degrade the quality of organization services delivery and as result low level of beneficiary satisfaction is realize. 
According to Paul (2009) many organizations have been forced to apply various retention strategies such as increase remuneration and offering of various rewards following increased rate of employees' turnover.

Nonprofit organization employee's turnover is universal challenge of developing nations across all over the world (Suzuki, 1998). In today's competitive world high staff turnover problem is negatively affected the program and existence of nonprofit sectors that relied on human knowledge to undertake their regular operation. Paul, (2009) stated that nonprofit organization employee's turnover riches more than $26 \%$ in Kenya and highly hinder organizational performance. Indian Ocean tsunami hazard support organizations emphasized on relevance of qualified workers for effective service provision of humanitarian emergency relief operation to the people in need in conflicting area. Long period separation from family member and relatives resulted to high turnover rate affected humanitarian operation of non-profit organizations (Henry, 2004).According to the study of Duncan, (2008), employees' turnover is graver and concern of non-profit sector in Africa. He further stated that poor leadership; unhealthy work environment and low salary and remuneration are more aggravating the situation. Employee turnover resulted to interruption of operations, including high replacement and recruitment cost leads to the loss of efficiency and hampered beneficiary satisfaction including the depletion of the organization's intellectual capital.

Employee turnover is serious problem and leading determinant factors in Ethiopia that severely affected local nonprofit organizations fully dependant on foreign fund and reduced organizational performance and sustainability over the time. Many nonprofit organizations are subjected to severance and compensation payment for employees left the organization based on labor law proclamation no. 42/1993.Amina, (2014) argue that non-profit organization employee's turnover negatively affected materials and financial resource and success of project implementation. She further stated that nonprofit sectors spent at least one third of employee yearly salary to hire the new worker. Most of Nonprofit organization operates in the country particularly local non-profit organizations spent more money and time for the process of hiring and induction, training and development of new employees. According to Yared, (2015) statement on reason of turnover 58\% of employee resigned because of poor management and salary discrimination between staffs and $46 \%$ were terminated during the first six months of employment from Assosa field office.

Employee turnover jeopardize the attainment of organizational objectives. According to Grant, (2010) employees are the most impotent asset to the organization success and it is very necessary to build strong retention strategy and use of human capital management best practice. For many nonprofit organizations recruiting and retaining talented employee is serious challenge they faced for long period. Joyce. (2017) survey indicated that over $50 \%$ nonprofit organizations cannot calculate cost of employee turnover and not established or updated their human resource recruitment and retention policies. According to Jimma Zone Government and Non Government Organization forum (2016) report employee's turnover was basic challenge of humanitarian sector that resulted to poor achievement and affected their sustainability. When experienced staffs leave the job the ongoing of project activity is frozen or disrupted. The new employees also required adjustment time to fully undertake task like who leave the job. The frequent disruption of project operation hindered the attainment of objective and meeting the deadline which in turn hampered relationship between nonprofit organization and their donor. Therefore this paper aimed to identify factors influence employee turnovers of nonprofit sector operate in Jimma area to provide some recommendation on retention strategies.

\section{Objectives of the Study General Objectives}

To assess major influencing factors of employee turnover that affected nonprofit organization operates in Jimma area

\section{Specific Objectives}

1. To identify personal factors that contribute for employee turnover in nonprofit sector operates in Jimma area.

2. To investigate organizational push factors that contribute for employee turnover in nonprofit sectors operates in Jimma area.

3. To examine external pull factors that contribute for employee turnover in nonprofit sector operates in Jimma area.

\section{Empirical Researches}

The study finding by Molley A (2017) revealed that remuneration was important in explaining staff turnover. On average many employees become sticky to their jobs due to pay related factors and hence the reason for similar conclusion in this current study and remuneration is statistically significant predictor of staff turnover. The study recommended that the management of NGOs should appreciate the importance of remuneration and work environment in retention of employees and establish competitive human resource practices that are meant to control staff turnover. For example it is recommended to the management of NGOs in Afghanistan to conduct a market survey in order to establish the optimal remuneration levels for NGO employee in order to control for the 
detriments that are associated with staff turnover.

Yezina, T (2014) study finding identified that salary, benefit package, better opportunity in other institutions, promotion and poor managerial relations are some of the causes. Based on the findings the impacts of the turnover are work load on employees then trainees' dropout, increase cost of institutions and less quality training and service are mains. Thus the responsible body may find these findings worthwhile for corrective action.

The research finding of Mollyne.et el(2017) indicated that leadership ability and reward system positively influenced employee retention NGO's in Kenya. The corresponding change in retention can be explained by unit change in Leadership clarity with constant. The research found out that reward has positive influence NGOs employee retention in Kenya and recommend more policy developed around rewarding of employees

According to Joseph M (2016) study finding the main factors that affected the rate of employee turnover were recruitment policies, motivation, level of education and pay package. The above factors showed strong positive relationship with the depended variable, meaning that they greatly influenced the rate of employee turnover in the industry Joseph M (2016)

\section{Research methodology}

The study uses quantitative and qualitative research approach. Descriptive and explanatory research design was applied for this particular study. Descriptive research was selected to better describe the characteristic of population and phenomena under study. According to Sekeran, (2003) descriptive research design is to describe the characteristics of a selected phenomenon and involves the collection of data without manipulation of variables. Krueger and Newman (2006) also stated that the sole purpose of descriptive research is to provide an accurate and valid representation of the factors or variables that are relevant to the research questions. Therefore the study was identified and described factors influenced professional staff turnover and their effecting nonprofit organization sectors.

The target population of the study comprised of 110 workers who served in NGOs and which 86 employees of the five nonprofit sectors in Jimma area were selected. The sampling frame for this study was employees of the five selected nonprofit organizations in Jimma area. As Dawson (2009 stated considerations needed in determining sample size are: the nature of unites, size of population, size of questionnaire, availability of trained investigators, the conditions under which the sample is being conducted and the length of time for completion of the study. Each managerial level is represented as a stratum. Since the research population was completely homogeneous. Five nonprofit organizations with highest number of workers and more than three years service in study area were systematically selected from the sampling frame among twenty eight NGOs. Stratified random samplings involve dividing population into management level and then applying random sampling method to each subpopulation to form sample group. Simple random sampling technique was used to select employees' involved managerial level due to their knowledge in nonprofit organization employees' turnover. They are therefore vital for getting reliable and efficient data on the topic of interest. Thus, all employees under three managerial levels of selected 5 nonprofit sectors were included in the survey. According to Krejcie and Morgan, (1970) sample size determination table at $95 \%$ confidence level and 5.0\% margin of error, 86 samples was selected from 110 Population.

Table 1: Sample Size Selection

\begin{tabular}{|l|l|l|l|l|l|l|}
\hline \multicolumn{2}{|l|}{ Upper level } & \multicolumn{2}{|c|}{ Middle level } & \multicolumn{2}{|c|}{ Lower level } & Total \\
\hline Population & Proportion & Population & Proportion & Population & Proportion & \\
\hline 19 & $\mathbf{1 5}$ & $\mathbf{3 0}$ & $\mathbf{2 3}$ & $\mathbf{6 1}$ & $\mathbf{4 7}$ & $\mathbf{8 6}$ \\
\hline
\end{tabular}

Source: researcher field Survey 2018

The population is divided in to three strata and respondents were proportionally drown from each stratus because of number of sampled units in each strata is proportional to the size of the stratum; the probability of selection is the same for all strata in population. (Lower level=61/110*86=48) (Middle level=30/1 $1 * 86=23$ ) (Upper level $=19 / 110 * 86=15$ )

For this study standard self-administered tested questionnaire was used to collect data and distributed to employees of nonprofit organization respondents to complete the questionnaire. The questionnaire had two partsthe first focused on demographic or personal information (sex, age, level of education, position and year of services), while the second part questionnaire focused on the relevant interest to this study include factors influence employee's turnover in case of nonprofit sector. The constructs were measured on a five point Likert-type scale ranging from 1 (strongly disagree) to 5 (strongly agree). A Likert scale of 5 has been used where 1 is used as a lowest value and is assigned to the lowest or worst option with 5 as the highest value assigned to highest or the best option. Johns (2010) noted that in statistical terms the level of measurement of the response scale is ordinal rather than interval; that is, we can make assumptions about the order but not the spacing of the response options. Focus group discussant interview semi structured question and check list was prepared and used to facilitate the discussion attractive and towards the study objective.

The quantitative data that was gathered through survey was analyzed and the findings were interpreted using descriptive and inferential statistics. Correlation and regression analysis were used to reveal the cause and effect 
relationship of the identified variables

Reliability implies consistency of a study or measurement. Kothari (2004) stated that measuring instrument is reliable if it provides consistent results. Validity refers to how well a test measure what it is purported to measure (Dooley, 2005).In order to ensure the validity researcher was requested and received tested standard questionnaire from other researcher by customizing in to thesis them. Additionally pilot questionnaires were distributed to 10 employees of nonprofit organization and the feedback received from respondents has also been incorporated. The collected data has been verified for its reliability. Cronbach's coefficient alpha has been calculated.

Table 2: Reliability Statistics

\begin{tabular}{|l|l|l|}
\hline Factors & No of items & Cronbachalpha \\
\hline Personal Factor & 4 & 0.780 \\
\hline Push Factor & 5 & 0.788 \\
\hline Pull Factor & 5 & 0.809 \\
\hline
\end{tabular}

Source: researcher field Survey 2018

According to George \&Mallery (2003), the value of alpha should be greater than 0.75 to accept the instrument. As depicted in table 3.2 above, all factors that determine factors affected staffs turnover were above $70 \%$, therefore, the research tool was deemed reliable.

\section{Result and discussion}

Among the total 93 questionnaires distributed to respondents 86 were completed and submitted back to data collectors and researcher while two questionnaires were incomplete and the rest four not returned. Therefore (94\%) response rate was adequate for this study deemed to have given a superior questionnaire response rate.

\section{Descriptive analysis of factors influencing turnover intention Reason for joining and leaving NGOs}

The study findings revealed that $80(93 \%)$ respondents indicated that better salaries were the primary reason for hiring in NGOs. other73 (84\%) respondents pointed out that better career growth opportunity were the second reason they join nonprofit sectors. Good leadership need was indicated as a third reason by $70(81 \%)$ respondents while half number $43(50 \%)$ respondents expressed job security the fourth level reason why they preferred work in nonprofit organization. This depicted that majority of employee find nonprofit sector to obtain high salary deserve better career growth chance and work under good leadership environments respectively.

The majority $71(83 \%)$ respondents revealed that they want to leave their organizations. $15(17 \%)$ respondents were not wanting to leave their current organizations. Therefore, the study findings imply that there is high number of employees were ready to leave their current organization

Personal Factors Influence Turnover

Table 3: Personal Factors

\begin{tabular}{|c|c|c|c|c|c|c|c|c|c|c|c|}
\hline \multirow[t]{2}{*}{ Personal factors } & \multicolumn{2}{|c|}{ Strongly agree } & \multicolumn{2}{|c|}{ Agree } & \multicolumn{2}{|c|}{ Neutral } & \multicolumn{2}{|c|}{ Strongly disagree } & \multicolumn{2}{|c|}{ Disagree } & \multirow[t]{2}{*}{ Total } \\
\hline & $\mathrm{F}$ & $\%$ & $\mathrm{~F}$ & $\%$ & $\mathrm{~F}$ & $\%$ & $\mathrm{~F}$ & $\%$ & $\mathrm{~F}$ & $\%$ & \\
\hline Personal Business & 10 & 12 & 20 & 23 & 19 & 22 & 17 & 20 & 20 & 23 & 100 \\
\hline Health Problem & 12 & 14 & 12 & 14 & 20 & 23 & 20 & 23 & 22 & 26 & 100 \\
\hline Family Problem & 12 & 14 & 12 & 14 & 18 & 21 & 24 & 28 & 20 & 23 & 100 \\
\hline Friends and peer influence & 12 & 14 & 13 & 15 & 16 & 19 & 22 & 25.6 & 23 & 26.4 & 100 \\
\hline
\end{tabular}

Source: researcher field Survey 2018

The above table indicated that $23(26.4 \%)$ of respondents were strongly disagreed and $17(20 \%)$ disagree and believed employees were not leaved their jobs for own business. on the other side around 10(11\%) respondent agreed on business influenced turnover and equal number $12(14 \%)$ also were agreed as opening own business resulted to staff turnover and $19(22 \%)$ of respondents were in different.

$22(26 \%)$ of respondents were strongly disagreed health problem not cause for turnover and the nearest figure $20(23 \%)$ also disagreed and said employees were not terminated their job for health problem while $12(14 \%)$ of respondent strongly agreed and the same number of respondents also agreed and $20(23 \%)$ neutral

In addition 24(28\%) respondents strongly disagree and believed that family problem was not affected employees to leave and 20(23\%) respondent also agree employees were not leaves their job for the reason related to family problem. On the other side $12(14 \%)$ respondents strongly agree and said the staff was tormented their job due to family problem and $12(14 \%)$ respondents agree family problem caused to employee turnover while only small number 17 (21\%) were neutral.

Concerning friend and peer influence $23(26.4 \%)$ respondents were strongly disagreed that peer factor is not forced employee to turnover while $22(25.6 \%)$ of respondents disagreed that the staff were not leaved their job by friend influence. But25 (31\%) respondents were in agreement and believed employees leave their occupation by 
peer influence and $16(19 \%)$ of respondents neutral. Thus, we conclude that personal factors were not influenced employees' turnover for this particular study.

\section{Push factors affecting Turnover Intention}

Table 4: Push Factors

\begin{tabular}{|l|l|l|l|l|l|l|l|l|l|l|l|l|}
\hline \multirow{2}{*}{ Personal factors } & \multicolumn{2}{l}{$\begin{array}{l}\text { Strongly } \\
\text { agree }\end{array}$} & \multicolumn{2}{l|}{ Agree } & \multicolumn{2}{l|}{ Neutral } & \multicolumn{2}{l|}{$\begin{array}{l}\text { Strongly } \\
\text { disagree }\end{array}$} & \multicolumn{2}{l|}{ Disagree } & Total \\
\cline { 2 - 15 } & $\mathrm{F}$ & $\%$ & $\mathrm{~F}$ & $\%$ & $\mathrm{~F}$ & $\%$ & $\mathrm{~F}$ & $\%$ & $\mathrm{~F}$ & $\%$ & \\
\hline Ineffective Management & 12 & 14 & 40 & 46 & 19 & 22 & 13 & 15 & 13 & 15 & 100 \\
\hline Low Salary and Benefit Package & 17 & 20 & 29 & 33 & 14 & 17 & 13 & 15 & 13 & 15 & 100 \\
\hline Lack of Career Growth Chance & 20 & 23 & 24 & 28 & 18 & 21 & 12 & 14 & 12 & 14 & 100 \\
\hline $\begin{array}{l}\text { Weak Relationship with } \\
\text { Coworkers }\end{array}$ & 10 & 12 & 12 & 14 & 22 & 25 & 20 & 23 & 22 & 26 & 100 \\
\hline Job related factors & 8 & 9 & 16 & 19 & 22 & 25.5 & 22 & 25.5 & 18 & 21 & 100 \\
\hline
\end{tabular}

Source: researcher field Survey 2018

The result shows that majority number $40(46 \%)$ of respondents were agreed $12(14 \%)$ strongly agreed that lack of good management leads to staff turnover. On the other side13 (15\%) respondents strongly disagreed and the same figure13 (15\%) disagreed that poor management were not cause for turnover while only small $8((9 \%)$ remain neutral.

The above figure indicated that $29(33 \%)$ and $17(20 \%)$ of respondents were agreed and strongly agreed respectively that insufficient salary and fringe benefit were key reason for employee turnover. 13(15\%) of respondents disagreed for the question low salary and benefit package influence employee turnover and the same number13 (15\%) of respondents also strongly disagreed. only $14(17 \%)$ of respondents were in different.

Concerning factors related to career growth development opportunity majority of respondents $24(28 \%)$ agreed that lack of career growth and development opportunity in the organization were reason for employee turnover of nonprofit sectors 20(23\%) also strongly agreed. Other $12(14 \%)$ and equal number12 (14\%) of respondents were disagreed and strongly disagreed that lack of career growth development opportunity was not influence staff retention andonly $18(21 \%)$ of respondents were neutral.

For the question weak coworkers relation resulted to turnover $20(23 \%)$ of respondents were strongly disagreed and $22(26 \%)$ disagreed poor coworkers relationship is not reason for staff turnover while other $10(12 \%)$ respondents strongly agreed $12(14 \%)$ agreed that unhealthy relationship with coworker forced staff turnover and significant number respondents $21(24.5 \%)$ were not agreed nor disagreed.

Around the majority $22(25.5 \%)$ of respondent were strongly disagreed and18 (21\%) disagreed and believed that job related factors were not influence employees to leave their jobs. Again $16(19 \%)$ of respondents were agreed and $8(9 \%)$ strongly agreed that job related factors were the main influence of employees to leave their jobs and $22(25.5 \%)$ respondents were stay neutral.

\section{Pull Factors for Turnover}

Table 5: Push Factors Affect Turnover Intention

\begin{tabular}{|c|c|c|c|c|c|c|c|c|c|c|c|}
\hline \multirow[t]{2}{*}{ Personal factors } & \multicolumn{2}{|c|}{$\begin{array}{l}\text { Strongly } \\
\text { agree }\end{array}$} & \multicolumn{2}{|c|}{ Agree } & \multicolumn{2}{|c|}{ Neutral } & \multicolumn{2}{|c|}{$\begin{array}{l}\text { Strongly } \\
\text { disagree }\end{array}$} & \multicolumn{2}{|c|}{ Disagree } & \multirow[t]{2}{*}{ Total } \\
\hline & $\mathrm{F}$ & $\%$ & $\mathrm{~F}$ & $\%$ & $\mathrm{~F}$ & $\%$ & $\mathrm{~F}$ & $\%$ & $\mathrm{~F}$ & $\%$ & \\
\hline Good Management external & 14 & 16 & 20 & 23 & 19 & 22 & 18 & 21 & 18 & 21 & 100 \\
\hline Better salary and benefits & 10 & 12 & 19 & 22 & 20 & 23 & 20 & 23 & 17 & 20 & 100 \\
\hline $\begin{array}{l}\text { Better career and development } \\
\text { opportunity }\end{array}$ & 7 & 9 & 20 & 23 & 15 & 17 & 20 & 23 & 24 & 27 & 100 \\
\hline Better organizational culture & 10 & 12 & 17 & 19 & 9 & 11 & 20 & 23 & 30 & 35 & 100 \\
\hline Better location of the organizations & 12 & 14 & 16 & 19 & 16 & 18 & 12 & 14 & 30 & 35 & 100 \\
\hline
\end{tabular}

Source: researcher field Survey 2018

As show in the above table $18(21 \%)$ and other equal number18 (21\%) of respondents were disagreed and strongly disagreed respectively better management is not attract employee to leave their jobs while 20 (23\%) of respondents and $14(16 \%)$ were agreed and strongly agreed that external organizations better management forced the staffs to leave their jobs. As well as around 19(22\%) respondents were neutral. Then we concluded that external organization better management was not affected employees to leave the organization.

Concerning attractive salary and benefit the majority $20(23 \%)$ as well as $17(20 \%)$ of respondents were disagreed and strongly disagreed respectively and believe that better salary of external organization was not cause for employees turnover unlike $19(22 \%)$ and 10(12\%) respondent agreed and strongly agreed respectively and believe attractive salary of other organization forced staffs to leave their work and $(23 \%)$ respondents were not 
agreed or disagreed.

The majority of respondents $30(35 \%)$ and 20(23\%) were disagreed and strongly disagreed that better career growth opportunity not resulted to staff turnover intention. but $17(19 \%)$ and $10(12 \%)$ of respondents were agreed and strongly agreed that better career growth chance in other organization definitely forced workers to leave their jobs frequently but the rest of $9(11 \%)$ respondents were not agreed or disagreed.

In response to organizational culture question $30(35 \%)$ respondent were disagreed that better organizational culture were not forced the staffs to turnover and $12(14 \%)$ of respondents were strongly disagreed while only $(10.3 \%)$ were not agreed or disagreed whether better organizational culture forced the staffs to leave.

The majority $30(35 \%)$ and $12(14 \%)$ of respondents disagreed and strongly disagreed and believes that location of other organization were not attracted employees to leave their jobs and other 16(19\%) and 12(14\%) were agreed and strongly agreed and said staffs were leaved their job due to better position of other organization as well as $16(18 \%)$ respondents preferred neutral.

\section{Conclusion}

Staff retention is vital for any organization to effectively attain objective and various factors were identified as cause of employee's turnover by many researchers in different study. In this paper the study concluded that internal push factors includes ineffective management and lack of career development opportunity and low salary and benefit as well as job related factors taken as major factors that forced employees to the exit door and contributed to high staff turnover in NGOs sector operate in Jimma area.

The study concluded that ineffective management skill, inadequate human resource policies and strategies are mentioned as internal factors that contributed to high staff turnover or affected retention in nonprofit sectors. The absence of efficient management practice in the organization resulted to leave professional staff their jobs. Poor management ability contributes to employee turnover and cause to employees looking to exit door before the end of contract period. Employees also not feel valued and leave their jobs and hence high staff turnover. Focus group discussants also identified inability of human resource department to prepare effective staff retention policy and strategy factor that affects employee to stay in the organization. They further stated discrimination, nepotism and unfair reward system, corruption and lack of proper salary and career advancement which increased staff turnover.

The study concludes that lack of career development opportunity increased staff turnover significantly in nonprofit sector operates in Jimma area. Even though professional development opportunity used as one important strategy to reduce staff turnover nonprofit sectors in the study area cannot recognize career growth path to acquire professional knowledge, skills, capability and attitude that enable employees to stay in the organizations for long time. The study shows that there is significant relationship between career advancement opportunity and staff turnover intention.

The majority of respondents point out that less payment and fringe benefiting nonprofit sectors is main factor that led employees to leave an organization. Low salary payment package played significant role to decline employee retention rate and losing experienced staffs. Lack competitive salary packages with little or no fringe benefits in nonprofit sectors forced workers to leave the NGOs. Focus group discussant identified that poor salary and allowance related to transport, housing and telephone was expressed as one of the various factors that contributed to employee dissatisfaction and desire to leave.

\section{Recommendation}

Top management should reduce staff turnover through improving organizational management and establish organization specific human resource policy to retain the best employees. The management should develop organization specific policy and review the policy through involvement of employees to meet the need rather than copied from other organizations. Employee involvement may be through meeting with their representatives. Nonprofit sector should invest and design leadership development program to improve the capacity of human resource management based on the nature of problem to reduce staff turnover intention.

Organization management should formulate and revise salary and benefit policy to coup up the frequent increase of inflation and price of goods in the market since attaining basic need like food and covering house rent fee is the sever headachy of employees in the country. Offering reasonable and marketable related payment will keep employees from leaving for better pay jobs and to remain in the organization as well as prevent cost invested for recruitment; training and orientation of new employee that affect the organization

The management should create opportunities for career advancement in the organization. Creation of opportunities for career advancement may help staff to become more competent and to enjoy their work even better. Top management should give due recognition to its internal employees when there are new positions within the organization. 


\section{References}

Amina, A.(2014): Factors influencing employee turnover in $N G O$ and challenge facing implementation of community based development project in Tanzania

Armstrong, M. (2006): A Hand Book of Human Resource Management, Tenth Edition, London, Kogan

Armstrong, M.(2009):Armstrong's handbook of human resource management practice London: Kogan Page, ISBN 978-0-7494-52421.

Dawson, S. (2009): Introduction to Research Methods book 4E4th Edition

Duncan,G.(2008):Employees Turnover and organization profitability: Journal of Human Resource Management Volume 12

Grant, R. (2010): Contemporary Strategy Analysis $7^{\text {th }}$ edition: Palgrave McMillan London

Harrie, G.(2002): Career Development Interventions in the 21st Century. Fifth Edition Columbus, OH: Merrill Prentice Hall.

Henry.Y.(2004):Comprehensive humanitarian sector information (www.peopleinaid.org)

Jimma Zone Go-NGO Forum (2016): Report of End Year Nonprofit Organizations Evaluation

Joseph,M.(2016):Factors influencing employee turnover in the hotel industry in Machakos town, A Research report in partial fulfillment of the requirement for the award of the degree of master of business administration of south eastern university Kenya

Joyce, N.(2017): Factors Affecting Employee Retention in Non-Governmental Organizations in Nairobi Kenya: Strategic Journals Business and Change Management Vol. 4, Issue. 2 (29), pp 496 - 509,

Kothari, C.(2004): Research Methods \& techniques. First Edition, New Age International Publisher

Krueger and Newman (2006): Social Work Research Methods: Qualitative and Quantitative Applications

Maxwell,F.(2010):Employees Turnover and organizational efficiency Journal of Personnel Management Volume 18

Molley,A.(2017):Influence of remuneration factors on staff turnover in humanitarian sector Human Resource and Leadership Journal Vol.2, Issue No.2, pp47- 63,

Paul, M. (2009): Employees Turnover in organizations Journal of Personnel Management Volume 18

Phillip, L. (2009): Employees Turnover \& organization efficiency Journal of Management Volume 22

Premeaux, P. (2006): Employees Turnover \& organization efficiency Journal of Management Volume 1

Suzuki, N.(1998):Inside NGO Learning to Manage Conflict between Headquarters and Field Staff Office: International Technology Publication: London

Taylor, D.(2010):CEO personal reputation: it affect remuneration during times of economic turbulence Procedia Economics and Finance, 2, 125-134. doi:10.1016/S2212-5671(12)00072-X

Thomas K.(2003): Managing people in modern work environments Journal of Management

Yared, D.(2015):Causes of Staff Turnover: in International Non-Governmental Organizations: A Case Study of (IRC): Thesis Paper for Degree of MBA in Addis Ababa University Faculty of Business and Economics, Addis Ababa University, pp 77-78

Yezina,T.(2014):Assessment on impact of employee turnover on TVET institutions A Thesis is submitted in Partial Fulfillment of the Requirements for Degree of Master of Arts in Management of Vocational Education. Addis Ababa University Ethiopia 